\title{
First findings from the UK Innovation Survey 2007
}

\section{SUMMARY}

This article presents the initial analysis of the 2007 UK Innovation Survey. It begins with patterns of innovation activity, looks at which markets innovative UK businesses are operating in, and then discusses collaborations and sources of information, the barriers to innovation and the methods used by firms to protect the value of innovations. A broader range of innovations in business practices and organisational structures, such as the introduction of new management techniques, is then considered. The article includes a few highlights from analysis of the panel (overlap) between the 2007 survey and its predecessor from 2005 and concludes with a comparison of the last three surveys from 2007, 2005 and 2001. his article presents the first findings from the UK Innovation Survey 2007, covering the three-year period from 2004 to 2006. This is the UK contribution to a Europe-wide Community Innovation Survey (CIS). The 2007 survey is the first one run on a new, biennial cycle. Previously, the survey was commissioned every four years.

The 2007 survey was sent to 28,000 UK enterprises with ten or more employees across manufacturing and services sectors, and achieved a 53 per cent response rate. The latest data also provide a significant panel (respondents common to both 2007 and 2005 surveys) of over 7,000 businesses, making it an even more valuable resource for both government and academic users. The Department for Innovation, Universities and Skills (DIUS) would like to thank all those businesses that completed the survey form.

The importance of innovation in business and in national economic performance is reflected in one of the Department's strategic objectives to 'accelerate the commercial exploitation of creativity and knowledge, through innovation and research, to create wealth, grow the economy, build successful businesses and improve quality of life'. Measuring the level of, and trends in, innovation activity in the UK and thus identifying where there may be shortfalls or gaps in the functioning of the innovation system, helps to show where policy measures might be required that could have some impact, and contributes to this mission. The UK Innovation Survey complements other indicators of innovation by providing a periodic snapshot of the spectrum of innovation inputs and outputs and the constraints faced by UK businesses in their innovation efforts, across the entire range of $\mathrm{UK}$ industries and business enterprises. It has the additional benefit of providing the basis for some comparisons with other countries.

The majority of the survey is concerned with innovation through new and improved products and processes and with the investments that develop and implement them. It also asks businesses about the drivers to innovate, as well as their perception of barriers to innovation. The markets businesses operate in, exports, changes in businesses structures and management practices, and the roles of knowledge are also covered.

\section{Innovation activity}

Innovation takes place through a wide variety of business practices, and a range of indicators can be used to measure its level within the enterprise or in the economy as a whole. These include the levels of effort employed (measured through resources allocated to innovation) and of achievement (the introduction of new or improved products and processes). This section reports on the types and levels of innovation activity over the three-year period 2004 to $2006^{1}$ and makes some general comparisons with the results obtained from the previous survey in $2005 .^{2}$ 
Table 1

Innovation-active enterprises: by type of activity, 2004 to 2006

\begin{tabular}{|c|c|c|c|}
\hline & \multicolumn{3}{|c|}{ Percentage of all respondents } \\
\hline & \multicolumn{3}{|c|}{ Size of enterprise (employees) } \\
\hline & $10-250$ & $250+$ & All \\
\hline Innovation-active & 63 & 74 & 64 \\
\hline Product innovator & 22 & 30 & 22 \\
\hline of which (share with new-to-market products) & 34 & 46 & 34 \\
\hline Process innovator & 11 & 22 & 12 \\
\hline of which (share with new-to-industry processes) & 26 & 25 & 26 \\
\hline Abandoned activities & 5 & 12 & 6 \\
\hline On-going activities & 8 & 15 & 8 \\
\hline Innovation-related expenditure & 54 & 65 & 55 \\
\hline Both product and process innovator & 8 & 16 & 9 \\
\hline Either product and process innovator & 25 & 36 & 26 \\
\hline
\end{tabular}

\section{Figure 1}

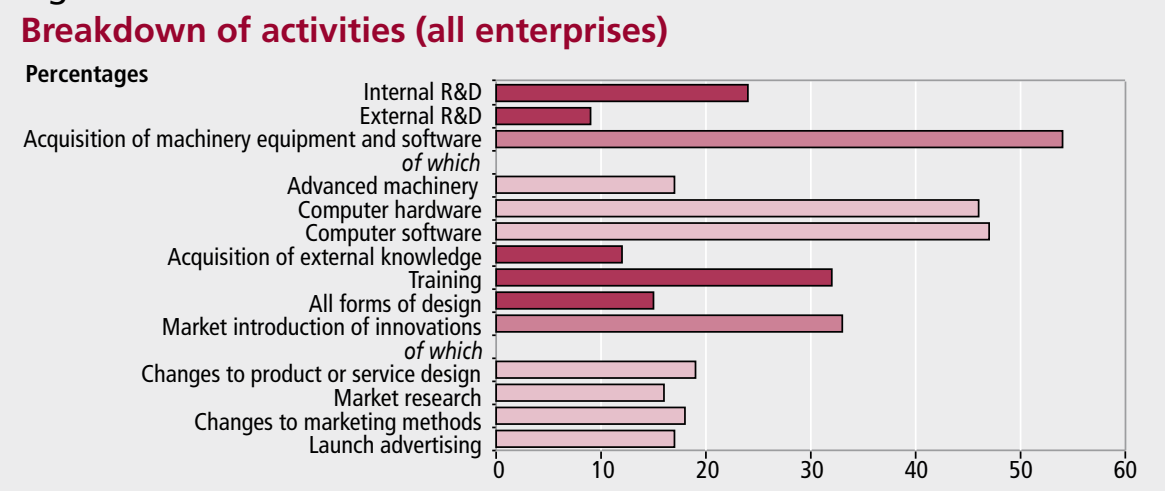

\section{Figure 2}

\section{Geographical markets}

\section{Percentages}

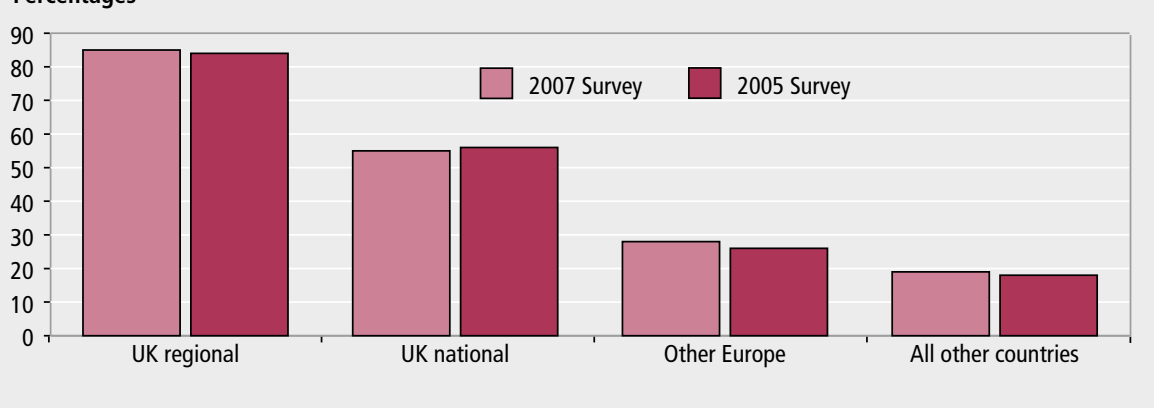

Innovation activity ${ }^{3}$ is defined here as where enterprises were engaged in any of the following:

- introduction of a new or significantly improved product (goods or service) or process

- engagement in innovation projects not yet complete or abandoned

- expenditure in areas such as internal research and development, training, acquisition of external knowledge, or machinery and equipment linked to innovation activities

From Table 1, overall, 64 per cent of enterprises were classed as being innovation-active during this period. Large enterprises (with 250 or more employees) were more likely to engage in some sort of innovation activity, with three-quarters of firms innovation-active, compared with nearly two-thirds of smaller enterprises.

In total, 22 per cent of enterprises had introduced new or significantly improved goods or services in the sample period, of which 34 per cent were new to market, and 12 per cent had introduced a new or improved process for production or delivery, with over a quarter of these processes being new to the industry in question. The share with product (goods and services) and process innovation is considerably greater in larger enterprises.

A new feature of the 2007 survey is the ability to distinguish between ongoing and abandoned innovation activities, previously combined into one question. Around a tenth of firms have projects ongoing and 6 per cent of enterprises report abandoned projects.

The proportion of enterprises having participated in some innovation-related activity (55 per cent) shows that firms recognise the need to assign resources to innovation. The 2007 survey disaggregated the combined activities question into 'acquisition of machinery, equipment and software' and 'marketing', as shown in Figure 1. The most commonly reported activities were in acquisition of computer software and hardware, followed by a considerable investment in training. While the single most frequent marketing-related activity is changes to product or service design, most respondents reported more than one of these activities.

Summing up, these early results seem to suggest that a larger share of enterprises is participating in just one mode of innovation behaviour, such as expenditure in an innovation-related activity. In contrast, results from the previous survey found more businesses were participating in several modes of innovation, such as combining product innovation and expenditure.

\section{Markets and exports}

The businesses surveyed were asked which markets they operated in. Figure 2 shows that over half of UK enterprises operate at a national level, nearly a third at European level and just under a fifth worldwide. Overall, higher proportions of businesses surveyed in 2007 operated in markets outside the UK (particularly Europe) than those surveyed in 2005.

Just under a quarter (23 per cent) of businesses reported any exports for the year 2006. The estimated average value of exports for these businesses was in excess of $£ 7$ million.

\section{Co-operation agreements and sources of information}

Ten per cent of all enterprises had cooperation arrangements on innovation activities and, of these, 70 per cent had agreements that operated at a national level. The most frequent partners for co-operation were clients or customers ( 68 per cent of enterprises with co-operation agreements) and suppliers (also at 68 per cent). Around 30 per cent of collaborators included universities amongst their partners. Innovation-active enterprises were more likely to collaborate ( 15 per cent). Figure 3 shows the proportions collaborating. 


\section{Figure 3}

\section{Co-operation partners (innovation-active, collaborative firms only) Percentages}

Suppliers of equipment, materials, services, or software Clients or customers

Other business within your enterprise group Competitors or other businesses in your industry Consultants, commercial laboratories, or private R\&D institutes Universities or other higher education institutions Government or public research institutes

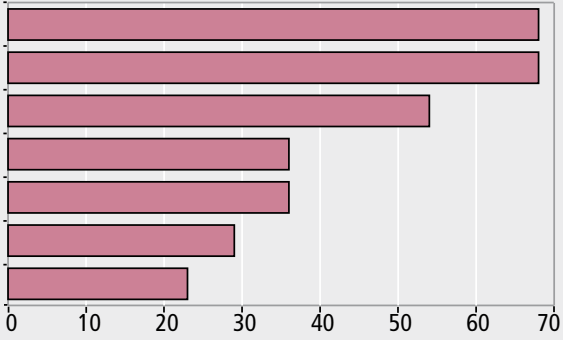

Table 2

\section{Sources of information: firms rating 'high'}

Percentage of all respondents

\begin{tabular}{cccc}
\hline & \multicolumn{3}{c}{ Size of enterprise (employees) } \\
\cline { 2 - 4 } - & $10-250$ & $250+$ & All \\
\hline
\end{tabular}

Internal
Within your enterprise group

18

33

Market

Clients or customers

Suppliers of equipment

Competitors or other enterprises within your industry

Consultants, commercial labs or private R\&D institutes

Institutional

Universities or other higher education institutes

Government or public research institutes

Other sources

Technical, industry or service standards

Conferences, trade fairs, exhibitions

Scientific journals and trade/technical publications

Professional and industry associations

$\begin{array}{rrr}27 & 37 & 27 \\ 14 & 18 & 14 \\ 10 & 17 & 10 \\ 2 & 4 & 2\end{array}$

\section{Figure 4}

Innovative businesses: by industry

Percentages PRODUCTION AND CONSTRUCTION Electrical and optical equipment Fuels, chemicals, plastic, metals and minerals Manufacturing not elsewhere classified Food, clothing, wood, paper, publishing and printing Electricity, gas and water supply Construction Mining and quarrying DISTRIBUTION AND SERVICES Real estate, renting and business activities Financial intermediation Wholesale trade (including cars and bikes) Retail trade (excluding cars and bikes)

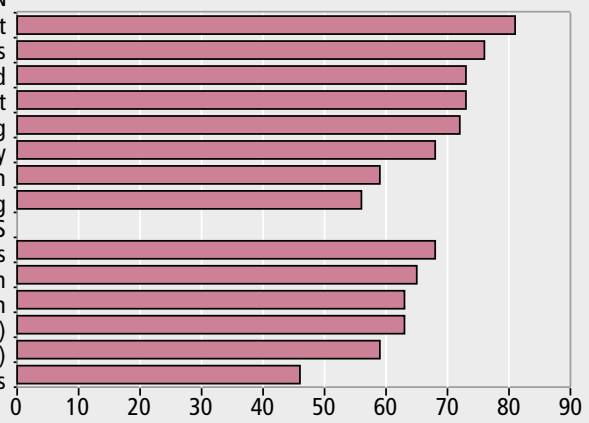

Figure 5

Shares of innovation-active businesses: by region
Percentages

$$
\begin{array}{r}
\text { Eastern England } \\
\text { East Midlands } \\
\text { North West England }
\end{array}
$$

South West England

Yorkshire and the Humber

$$
\begin{array}{r}
\text { Wales } \\
\text { England }
\end{array}
$$
West Midlands Scotland

North East England Northern Ireland London

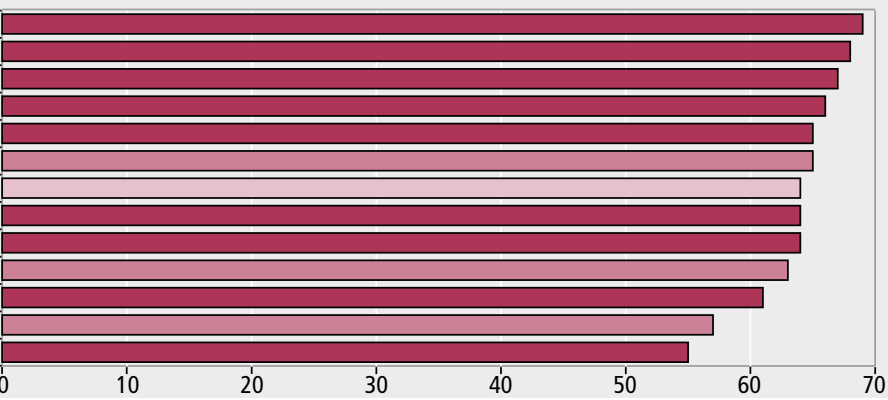
Transport, storage and communication Hotels and restaurants

South East England

\section{Sources of information}

It is important to know how far enterprises engage with external sources of technology and other innovation-related knowledge and information, as innovation is increasingly complex, requiring the coordination of multiple inputs. Firms can gain guidance, advice or even inspiration for their prospective innovation projects from a variety of both public and private sources.

Respondents were asked to rank a number of potential information sources on a scale from 'no relationship' to 'high importance. The proportion who answered 'high' in each category is shown in Table 2. These sources are:

- internal - from within the enterprise itself or other enterprises within the enterprise group

- market - from suppliers, customers, clients, consultants, competitors, commercial laboratories or research and development enterprises

- institutional - from the public sector such as government research organisations and universities or private research institutes, and

- other - from conferences, trade fairs and exhibitions; scientific journals, trade/technical publications; professional and industry associations; technical industry or service standards

Both larger and smaller enterprises reported market and internal sources as most important for information on innovation. This suggests that enterprises tend to rely on their own experience and knowledge coupled with information from suppliers, customers and clients. The least frequently cited sources were institutional sources. Technical, industry or service standards were also a highly important source for 12 per cent of large firms.

\section{Industrial and regional variation}

The percentage of firms reported to be innovation-active varied considerably across industrial and commercial sectors (Figure 4). In the production and construction sector, 81 per cent of electrical and precision engineering enterprises were innovation-active, against 56 per cent of enterprises in mining and quarrying. In distribution and services, real estate, renting and business activities (which include the $\mathrm{R} \& \mathrm{D}$ services sector) had the highest share of innovation-active businesses (68 per cent), against only 46 per cent for hotels and restaurants. 
Figure 5 shows the shares of innovationactive businesses across the countries and regions of the UK. The 2007 data exhibit greater regional variation in the proportions than did the 2005 survey, ranging from almost 70 per cent in Eastern England, the region in 2005 that recorded the lowest levels of innovation activity, to 55 per cent in London. Regional data reflect greater industrial variation and industries follow their own business cycles which could explain these differences. At country level, England, Wales and Scotland all performed similarly, with Northern Ireland slightly lower (around 6 percentage points less).

\section{Factors driving innovation}

On this occasion, the survey sought information about motivation factors for innovation (whereas previous surveys have asked about the effects of innovation).

Respondents were asked to rank a number of drivers for innovating on a scale from no impact, through low, medium or high. Looking at the proportion of innovation-

Table 3

\section{Enterprises regarding potential barriers to innovation as 'high'}

Percentage of all respondents Size of enterprise (employees)

\begin{tabular}{lrrr}
\hline & \multicolumn{3}{c}{ Size of enterprise (employees) } \\
\cline { 2 - 4 } & $10-250$ & $250+$ & All \\
\hline
\end{tabular}

\section{Costs factors}

Direct innovation costs too high

Excessive perceived economic risk

Cost of finance

Availability of finance

$\begin{array}{rrr}10 & 12 & 10 \\ 8 & 10 & 8 \\ 9 & 7 & 9 \\ 7 & 6 & 7\end{array}$

\section{Knowledge factors}

Lack of qualified personnel

Lack of information on markets

Lack of information on technology

6
2

Market factors
Dominated by established enterprises

Uncertain demand

6

5

Other factors

UK regulations

EU regulations active respondents who answered high in each category points towards productreported, mirroring the results found from UK IS 2005 and verifying a strong Again, the objectives of increasing value-added in the business and meeting regulatory requirements were also widely

\section{Barriers to innovation} the barriers to business innovation. These barriers can be internal obstacles that the encounters while carrying out factors preventing innovation.

The survey asked about a range of constraining factors and their effect on the ability to innovate. Table 3 shows the proportions of respondents who gave a high rating to each category of constraint. interventions require an understanding of

\section{Figure 6}

Perception of barriers - comparison of innovators and non-innovators rating 'high' Percentages

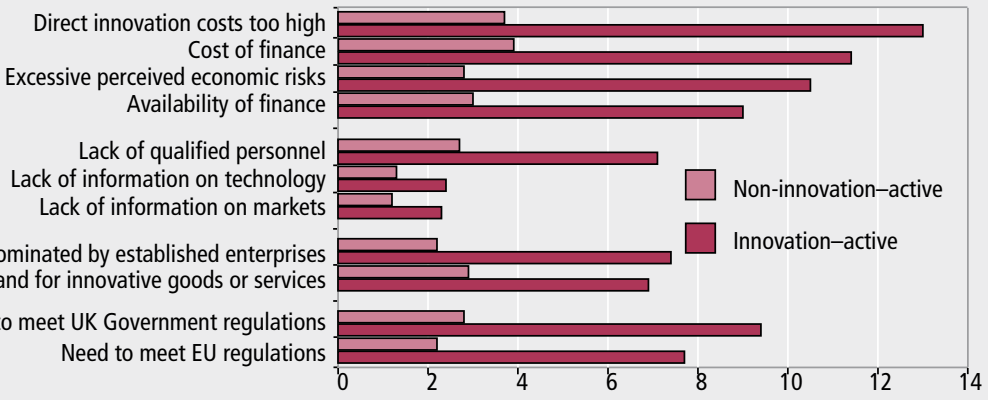

The 2007 data show an overall fall in the perception of barriers to innovate. However, relative to the other barriers, and as noted in the previous survey, cost factors were most commonly regarded as the most significant barriers to innovation, including the direct resource costs of innovation activities, their perceived economic risk and the costs of acquiring finance. The impact of $\mathrm{UK}$ and EU regulations was also identified as a barrier to innovation, independent of enterprise size. Again, relatively few enterprises felt constrained by a lack of knowledge, while a lack of qualified personnel was viewed as one of the more important constraining factors. Larger enterprises also expressed some concerns regarding market factors.

It is striking that, across most categories, those enterprises engaged in innovation activity were, on average, more than twice as likely to perceive barriers as businesses who did not attempt to innovate (Figure 6). Exceptions are knowledge factors. Neither technology nor market knowledge are widely cited as constraints on effective innovation. These results suggest that businesses learn about barriers to innovation as a result of their attempts to innovate.

\section{Non-innovators}

The survey also attempts to gain an appreciation of the possible reasons why businesses were not involved in innovation activity during the period 2004 to 2006 . The majority of non-innovators reported it was not necessary due to market-related conditions (Figure 7), although a quarter of non-innovators reported that particular constraints were sufficiently binding to prevent innovation.

\section{Methods to protect the value of innovations}

Successful innovations often generate intellectual property that businesses will try to protect. This can be done in numerous ways depending upon the knowledge generated and the business and market context. This may involve attempts to exercise formal intellectual property rights, but 'strategic' ways of preventing emulation are important for many firms.

The survey collected data on business perceptions of the relative importance of different means of protecting intellectual property, reported in Table 4 . These included formal intellectual property rights as well as strategic mechanisms such as being first to market. The data show that similar proportions of enterprises rated 
Figure 7

\section{Reasons why enterprises did not innovate (non-innovative enterprises only), 2004 to 2006}

Percentages

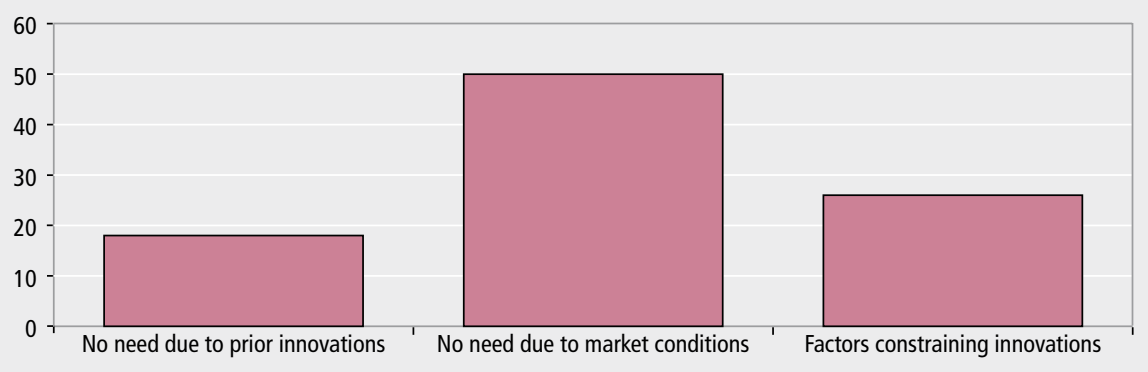

Table 4

Enterprises rating different methods for protecting innovation as of 'high' importance

Percentage of all respondents

\begin{tabular}{rrrr}
\hline & \multicolumn{3}{c}{ Size of enterprise (employees) } \\
\cline { 2 - 4 } & $10-250$ & $250+$ & All \\
\hline
\end{tabular}

Formal

Confidentiality agreements

Trademarks

Copyright

Patents

Registration of design

12
8

$26 \quad 13$

19

14

14

15

14

Strategic

Lead-time advantage on competitors

Secrecy

Complexity of design

10
8
4

strategic and formal methods as being of high importance, with the exception of confidentiality agreements, which were rated highly important by over a quarter of large firms. In fact, larger enterprises attached greater importance than smaller enterprises to all methods for protecting intellectual property, in the ratio of $2: 1$. It is not possible to determine from this survey if this is because large businesses have more intellectual property to protect or whether it is because large businesses have a greater awareness of intellectual property issues.

The Intellectual Property Office, along with the Gowers Review of Intellectual Property, ${ }^{4}$ have raised awareness of protection methods and, in general, the proportion of enterprises marking all methods as of 'high' importance, especially those classed as 'formal' protection methods, has increased on that recorded in the 2005 survey.

\section{Wider forms of innovation}

Innovation is not wholly about the development or use of technology or other forms of product (goods and services) and process change. Enterprises can also change their behaviour or business strategies to make themselves more competitive, often in conjunction with product or process innovation, but also as independent means of improving competitiveness.

Enterprises were asked whether they had made major changes to their business structure and practices in the three-year period 2004 to 2006. Some of the findings are summarised in Table 5. As would be expected, and as reported in 2005 , a far greater proportion of large firms engaged in one or more of these changes. Implementing new organisational structures was most commonly reported, with the introduction of advanced management techniques being least frequent. Small enterprises were half as likely to have introduced a major organisational change as large enterprises.

\section{Comparisons with the 2005 UK Innovation Survey panel}

The number of businesses responding to both the 2007 and 2005 surveys enables some direct comparison of their innovation activities and outturns. Of the 7,000 businesses in the 2007 survey panel, around half are small enterprises, with medium and large enterprises accounting for the other half in equal proportions. Figure 8 shows the innovation characteristics of the panel. A comparison with Table 1 shows that the 2007 panel results are broadly similar, 


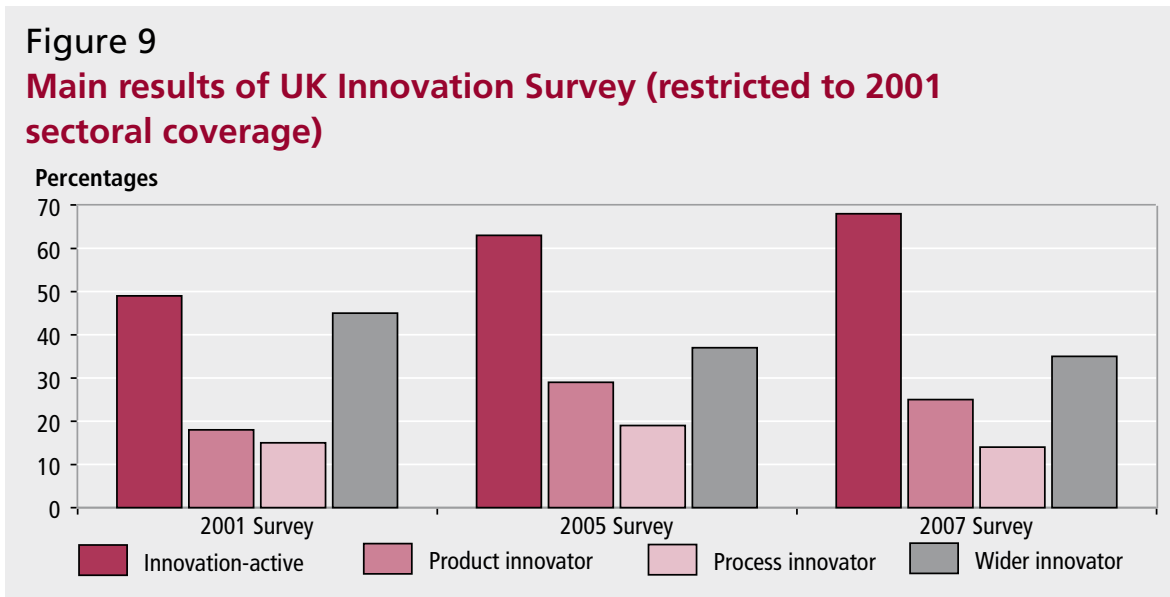

indicating that the panel is representative of the survey as a whole.

\section{Comparisons with the 2001 and 2005 UK Innovation Surveys}

There are now three broadly similar surveys enabling some time series analysis.

Figure 9 compares the main results for the three surveys based on the common sectoral coverage. ${ }^{5}$ Wider innovation activities were extensively reported in 2001, with increased product and process innovation being reported in 2005 . The 2007 survey reports higher shares of enterprises with preparatory expenditure on innovation. Results may also be affected by increased understanding by respondents of the survey. Respondents indicate that market conditions dominate their propensity to innovate. Increased investment reported in this survey may point to an upward trend in future levels of product and process innovations, to be captured in the next full survey to be conducted in 2009.

\section{Conclusions and next steps}

This short article has reported just a few of the results of the latest UK Innovation Survey and on some dimensions of the changes in innovation behaviour in the UK relative to the previous survey in 2005.

DIUS will publish more extensive detailed survey results over the next few months, as well as applying the innovation indicators to policy analysis and monitoring purposes.

The reports will include industrial and regional analyses that will enable the business community to benchmark their own innovation performance.

The survey represents a major source of data for the research community. As with previous surveys, a substantial body of further research is expected, using the survey results to be undertaken and published in various forms over the next few years.

\section{Notes}

1 All results are grossed up to the business population.

2 General comparisons refer to overall survey results. Other differences between the survey, such as the inclusion of SIC (2003) 92.1/2, variations in question wording and the overlap of the reference period (2006) in question, are not accounted for.

3 The UK definition used differs from that adopted by Eurostat. The EUwide definition of innovation-active is as follows: introduction of a new or significantly improved product (goods or service) or process; engagement in innovation projects not yet complete or abandoned. It excludes expenditure in areas linked to innovation activities.

4 The Gowers Review can be found at www.hm-treasury.gov.uk./media/6/E/ pbr06_gowers_report_755.pdf

5 Sectors covered in CIS3 were SIC (92) 10-14, 15-37, 40-41, 45, 50-51, 60-64, $65-67,70,71,72,73,74.2$ and 74.3 .

\section{CONTACT}

凶elmr@ons.gsi.gov.uk 


\section{APPENDIX}

\section{Methodology}

The UK Innovation Survey is funded by the Department for Innovation, Universities and Skills (DIUS). The survey was conducted on behalf of DIUS by the Office for National Statistics (ONS), with assistance from the Northern Ireland Department of Enterprise, Trade and Investment (DETI).

The UK Innovation Survey is part of a wider Community Innovation Survey (CIS) covering EU countries. The survey is based on a core questionnaire developed by the European Commission (Eurostat) and Member States. This is the fifth iteration of the survey (CIS 5) - CIS 4, covering the period 2002 to 2004, was carried out in 2005 and the results form part of various EU benchmarking exercises (see www.cordis.lu/innovation-smes/scoreboard/ home.htm).

The UK Innovation Survey 2007 sampled over 28,000 UK enterprises. The survey was voluntary and conducted by means of a postal questionnaire. A copy of the questionnaire used can be found at www.berr.gov.uk/files/file44938.pdf

\section{Coverage and sampling}

The survey covered enterprises with ten or more employees in sections $C$ to $K$ of the Standard Industrial Classification (SIC) 2003. The 2007 survey included additional sectors (SIC 92.1/2).

The sample was drawn from the ONS Inter-Departmental Business Register in January 2007.

\section{Response and weighting}

The questionnaires from the initial survey were distributed on 31 March 2007.

Valid responses were received from 14,872 enterprises, to give a response rate of 53 per cent.

The results in this article are based on weighted data in order to be representative of the population of firms. The responses were weighted back to the population using the inverse sampling proportion in each stratum, that is, the weight attributed to each enterprise was the number of enterprises in the population divided by the number of responses in that stratum. On average, each respondent represents 12 enterprises in the population. 